\title{
Effect of Nutmeg Administration on the Anterior Cingulate Cortex (Area 24a) of Adult Male Albino Rats and the Protective Role of Vitamin C: A Histological and Immunohistochemical Study
}

\author{
Wael B El-Kholy and Neveen M El-Sherif* \\ Department of Anatomy and Embryology, Menoufia University, Egypt
}

Submission: April 25, 2017; Published: May 30, 2017

*Corresponding author: Neveen M El-Sherif, Anatomy and Embryology Department, Faculty of Medicine, Menoufia University, Egypt, Email: neveensherif@yahoo.com

\begin{abstract}
Nutmeg is commonly used as a spice in various dishes, as components of teas and soft drinks or mixed in milk and alcohol. We investigated for the first time, the effect of chronic consumption of nutmeg on the anterior cingulate cortex of adult Wistar rats and the possible protective role of vitamin C. Adult male albino rats $(n=20)$, with average weight of 200 gms. were assigned into three groups: Control, nutmeg treated and protected. The whole experimental period lasted for 6 weeks. Animals of nutmeg treated group showed cellular degenerative changes relative to those in the control group. It was concluded that, long term consumption of nutmeg has adverse effect on microanatomy of anterior cingulate cortex. In the vitamin C-supplemented (Protected) group, there was improvement in the histological and immunohistochemical changes. Further research, including human observational studies, aiming at corroborating these observations is recommended.
\end{abstract}

Keywords: Nutmeg; Anterior cingulate cortex; Histological effect; Rat

Abbreviations: DAB: Diaminobenzoic Acid; ANOVA: Analysis Of Variance; GFAP: Glial Fibrillar Acid Protein

\section{Introduction}

The nutmeg tree (Myristicafragrans Houtt), which yields an apricot-shaped fruit, is a tropical aromatic evergreen tree. The fruit contains a nutmeg seed which is covered by a protective aril. The aril can be processed giving a spice called mace and the seed is processed to make nutmeg [1]. Being frequently used in baking and cooking, nutmeg is considered a common household spice. The market available forms of nutmeg include the volatile oils, ground powder, and whole nut. Moreover, nutmeg essential oils and butter are also obtained from M. fragrans. These products are widely used in the medicine, food, and perfume industries [2]. Nutmeg is commonly used in variable ways and for many purposes. Beside its traditional use as a spice, it is also used for many purposes in traditional medicine. Nutmeg is used less commonly in Western medicine than in Oriental medicine [3]. Recently, with the gain in popularity of herbal medicine all around the world, the abuse the use of M. fragrans is also possible because of its addictive properties. The spice ingestion in large quantities can be toxic may cause convulsions and even death. The use of nutmeg as a spice and its medicinal use suggest the presence of some components which are responsible for the noticed biological activities. Some of these active principles, as reported previously, may possess some adverse effects at the same time [4]. The main constituents of nutmeg are volatile oil, fixed oil and starch. The volatile oil contents are sabinene, pinene, elemicin, camphene, myristicin, isoelemicin isoeugenol, eugenol,methoxyeugenol, dimericphenylpropanoids, neolignans and lignans. The fixed oil contents are myristic acid and myristin. Phytochemical screening of the seed of M. fragrans aqueous extract revealed the presence of saponins, alkaloids, anthraquinones, cardiac glycosides, phlobatanins and flavonoids [1]. Dietary phytochemicals including polyunsaturated fatty acids, flavonoids and others have been the subject of increasing numbers of research studies for their potential beneficial effects and also because there is apparently increasing evidence that these compounds possess deleterious effects at certain doses. Many researches were done to study the effects of nutmeg on different organs such as liver, kidney, heart, spleen, testes, etc [4]. 
The medial part of the prefrontal cortex is represented by the anterior part of cingulate cortex (area 24). On the basis of the cingulate cortex lamination pattern, it can be classified into isocortex (area 1) and proisocortex (area 2) [5]. Some researchers [6] define area 1 as the dorsal anterior cingulate cortex and area 2 as the ventral anterior cingulate cortex, but other researchers [7] consider them as areas $24 \mathrm{~b}$ and 24a, respectively. The area 24 a (ventral anterior cingulate cortex) represents a transitional zone that displays stepwise changes in its architectonic lamination pattern between the characteristic allocortical structure and the typical isocortical zone [8]. As it lacks the granular cell layer (lamina IV), the ventral part of the anterior cingulate cortex has a prominent architectonic feature. This makes the differentiation between this region and rest of the neocortex clear [9]. It has several connections with many limbic structures as the amygdala, hippocampus, hypothalamus and thalamus [10]. The area 24a (ventral anterior cingulate cortex) is strategically involved in both autonomic visceromotor and cognitive functions [11].

Vitamin C (ascorbic acid) is an important dietary antioxidant of non enzymatic nature that acts to overcome oxidative stress. It is considered as one of the major water-soluble, antioxidant reducing agents within the body that acts as an electron donor, and probably all of its roles both biochemical and molecular can be explained by this function [12]. However, relatively high levels of this vitamin must be maintained in the body to function as an effective antioxidant [13]. This study was conducted to demonstrate the effect of nutmeg on the structure of the ventral anterior cingulate cortex (area 24a) in adult male albino rats, and to evaluate the protective role of vitamin $\mathrm{C}$ against the possible induced changes.

\section{Material and Methods}

\section{Experimental protocol}

This study was carried out on 20 adult male Wistar albino rats weighing 180-200 gms. Animals were housed in clean properly ventilated cages, fed on a standard laboratory diet, and maintained on a 12-h light/dark photoperiod in the animal house of the Faculty of Medicine, Menoufiya University. The animals were treated in accordance with the guidelines approved by the Animal care and Use Committee of Faculty of Medicine, Menoufiya University. Animals were randomly assigned into three groups:

Group I (Control): It included 10 animals that were equally subdivided into two subgroups:

a. Subgroup Ia (Negative control group) in which animals were kept without any treatment all over the experimental period.

b. Subgroup Ib (Positive control group) in which animals received vitamin $\mathrm{C}$ at a dose of $500 \mathrm{mg} / \mathrm{kg} /$ day orally for 6 weeks.
Group II (Nutmeg-treated group): This group included 5 animals that were treated daily with nutmeg. Animals were given $1 \mathrm{ml}$ of nutmeg extract at a dose of $500 \mathrm{mg} / \mathrm{kg} /$ day orally for 6 weeks.

Group III (Protected group): This group included 5 animals that received vitamin C 30 minutes before oral administration of nutmeg at the same dose and duration as the previous two groups.

At the end of the experiment, the animals were sacrificed by an overdose of ether and perfused intracardially with saline and $10 \%$ neutral-buffered formalin. The brains were extracted from the skulls. The anterior cingulate cortex was dissected by a coronal cut rostral to the corpus callosum.

\section{Preparation of the nutmeg seed's extract}

Nutmeg seeds were obtained from local nearby markets. To remove fungal spores, dust and/or other undesired particles; the dry seeds were washed thoroughly then left to dry, overnight, under room temperature. Using a mortar and pestle; the seeds were then macerated into a fine flour-like paste to pass through $0.2 \mathrm{~mm}$ mesh. Then we used aliquot weight of nutmeg powder (1gm) which, then, was soaked in $2 \mathrm{ml}$ hot distilled water and left to stand for $72 \mathrm{hrs}$ and then the extract was filtered. That extract was kept a frozen form until used [4].

\section{Histological Procedures}

Brains in each group were fixed in $10 \%$ neutral formalin for $48 \mathrm{~h}$. Tissues were dehydrated in ascending concentrations of alcohol, cleared in xylene, and embedded in paraffin. Fivemicrometer-thick sections were prepared. Sections were stained with Hematoxylin and Eosin (H\&E) stain [14]

For immunohistological staining, paraffin sections (5 $\mu \mathrm{m}$ thick) were deparaffinized in xylene for 1-2 min and then rehydrated in descending grades of ethanol $(100 \%, 95 \%$, and $70 \%$ ethanol) two changes 5 min each, then brought to distilled water for another $5 \mathrm{~min}$. Sections were rinsed with PBS, blocked for $30 \mathrm{~min}$ in $0.1 \% \mathrm{H} 2 \mathrm{O} 2$ as inhibitor for endogenous peroxidase activity. After rinsing in PBS, sections were incubated for 60 min in blocking solution ( $10 \%$ normal goat serum) at room temperature. The sections were then incubated with the primary antibody (iNOS 1:500; Bax-protein 1:500; Bcl-2 protein 1:500; TNF- $\alpha$ 1:1000 and GFAP 1:300) at room temperature for an hour. Sections were rinsed with PBS, followed by 20 min of incubation at room temperature with secondary biotinylated antibody. After rinsing the sections in PBS, enzyme conjugate "StreptavidinHorseradish peroxidase" solution was applied to the sections for $10 \mathrm{~min}$. Secondary antibody binding was visualized using 3,3'diaminobenzoic acid (DAB) dissolved in PBS with the addition of $\mathrm{H} 2 \mathrm{O} 2$ to a concentration of $0.03 \%$ immediately before use. Finally, sections were PBS rinsed and counterstaining of slides was done using two drops of hemotoxylin. Slides were washed in distilled water until the sections turned blue. Finally, slides 
were dehydrated in ascending grades of ethanol (70\%, 95\%, and $100 \%$ ) for 5 min each and were cleared in xylene and finally coverslipped using histomount mounting solution.

\section{Morphometric procedure and statistical analysis}

In this work, an estimation of the number of immunopositive cells per area $(3000 \mu \mathrm{m} 2)$ in the second layer (external granular layer) and third layer (pyramidal layer) of the cingulate cortex was made for all the studied groups. The number of immunopositive cells in the fields was counted using image J software and averaged per field for each animal. The numbers calculated for five animals/experimental group were considered for comparison and statistical analyses. The statistical analysis for each experimental parameter was performed using the arithmetic mean, standard deviation $(\mathrm{X} \pm \mathrm{SD})$, and analysis of variance (ANOVA). This was followed by Tukey's test for multiple comparisons. $\mathrm{P}$ values less than 0.05 were considered significant.

\section{Results}

There was no significant difference between the animals of the two subgroups of Group I in all the outcomes used in the study; therefore, these two subgroups were pooled in one group (control).

\section{Group I (control)}

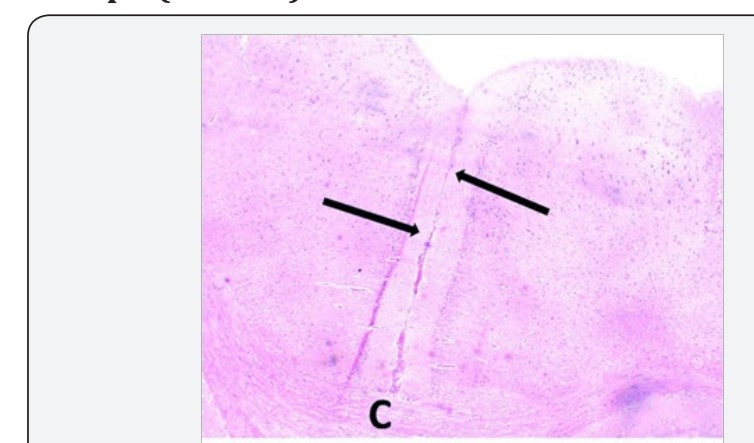

Figure 1: A photomicrograph of a coronal section from an adult control rat brain showing the position (arrows) of the ventral anterior cingulate cortex (area 24 a). Note that it is located on the medial surface of the cerebral hemisphere just above the corpus callosum (C). H\&E, $\times 40$.

The ventral anterior cingulate cortex (area 24a) is located just above the corpus callosum. It represents the medial part of the prefrontal cortex (Figure 1) and is composed of the following layers: layer I (molecular layer) - it contained sparsely scattered cells and nerve processes; layer II (external granular layer) - it contained packed rounded cells with rounded nuclei and distinct nucleoli; layer III (pyramidal layer) - this layer showed the presence of dispersed pyramidal cells of various sizes; layer IV - this layer was absent. Layer V (ganglionic layer), consisted of many pyramidal cells. Many nerve processes could be observed extending from the cells. Layer VI (multiform layer) contained cells of different sizes and shapes (Figures $2 \& 3$ ).

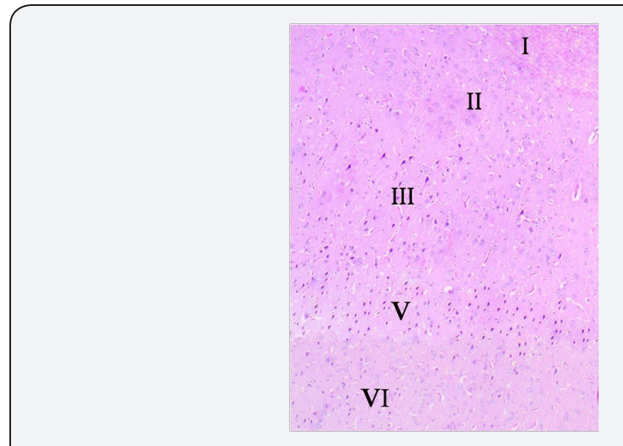

Figure 2: A photomicrograph of a section of anterior cingulate cortex (area 24a) from an adult control rat (group I) showing its various layers: layer I (molecular layer), layer II (external granular layer), layer III (pyramidal layer), layer V (ganglionic layer), and layer VI (multiform layer). Note the absence of layer IV (internal granular layer). H\&E, × 100.

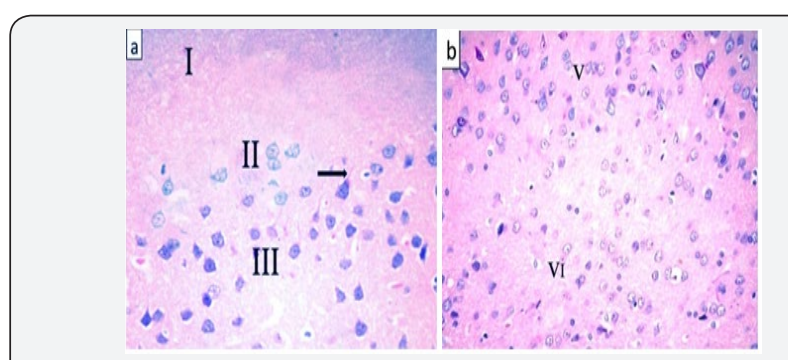

Figure 3: Photomicrographs of a section of anterior cingulate cortex from an adult control rat showing (a) layers I, II, and III. Layer I is mainly composed of nerve processes and a few scattered cells. Layer II has many rounded cells with rounded nuclei and prominent nucleoli. Layer III is mainly formed of pyramidal cells with oval vesicular nuclei. Arrow pointed to the process of a nerve cell. (b) Layer $\mathrm{V}$ is composed of large pyramidal neurons that have large soma with long extended processes. The cells have oval vesicular nuclei with prominent nucleoli. Layer VI has cells of various shapes and sizes. H\&E, $\times 400$.

\section{Group II (Nutmeg-treated rats)}

Sections of the ventral anterior cingulate cortex showed the presence of many cells with vacuolated cytoplasm in its layers. Some cells with pyknotic nuclei could be seen. Dilatation and congestion of blood vessels was clearly noted (Figure 4).

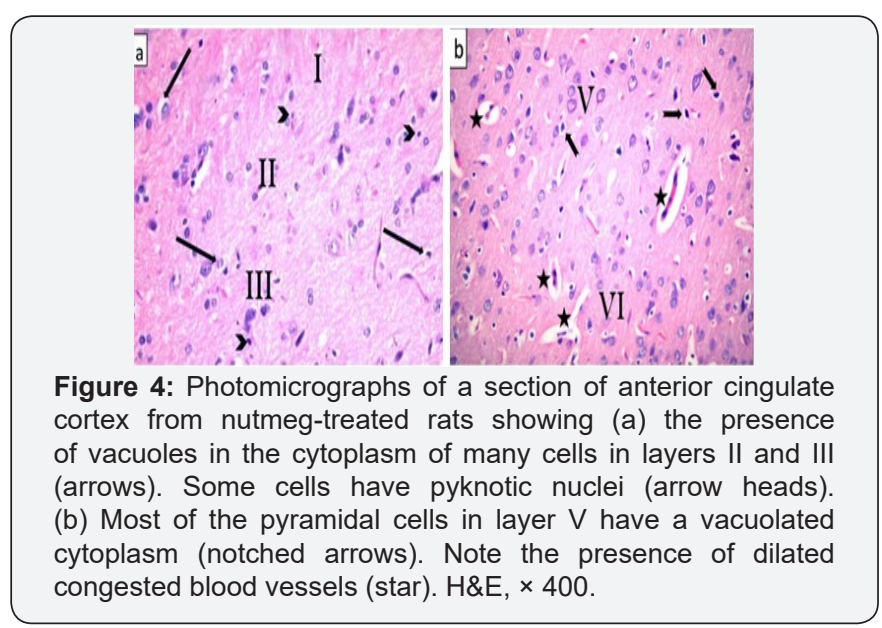




\section{Group III (Protected rats)}

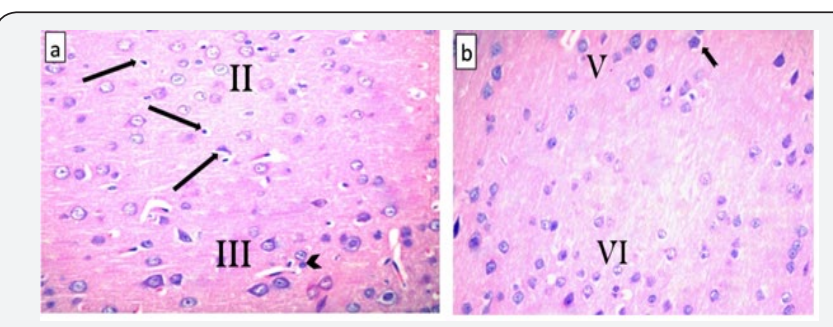

Figure 5: Photomicrographs of a section of anterior cingulate cortex from protected rats showing (a) normal appearance for most of the cells in layers II and III. Note the presence of some cells with vacuolated cytoplasm (arrows). Few cells with pyknotic nuclei can be seen (arrow head). (b) Most of the pyramidal cells inlayer $\mathrm{V}$ appeared to be nearly similar to those of controls. Some cells have vacuoles in their cytoplasm ((notched arrows). H\&E, $\times 400$.

Light microscopic examination revealed that most of the cells in the ventral anterior cingulate cortex had a normal appearance. However, some cells with a vacuolated cytoplasm were also present. Few cells with pyknotic nuclei could be seen (Figure 5).

Quantitative immunohistochemical assessment and statistical analysis was performed (Figure 6). A significant up- regulation of iNOS expression, a marker of oxidative distress was detected in the nutmeg treated group compared with control group $(13.93 \pm 6.39 \mathrm{vs} 00 \pm 00)$. In the protected group, iNOS expression was significantly down-regulated compared with nutmeg treated rats $(3.37 \pm 0.56)$. The elevated expression of iNOS was associated with a significant increase in the number of Bax-protein positive cells in the nutmeg treated group compared with controls (13.6 \pm 6.4 vs $0.3 \pm 0.28)$, which was significantly reduced in the protected group $(2.18 \pm 0.56)$. There was a significant decrease in Bcl-2 protein activity in nutmeg treated rats compared with control rats $(13.58 \pm 6.41$ vs $53.87 \pm 3.91$ ). Interestingly, in the protected group, the decreased Bcl-2 protein expression was significantly increased in the cytoplasm of many nerve cells and endothelial cells of blood vessels $(26.55 \pm 1.47)$. The expression of the inflammatory marker TNF- $\alpha$ was significantly increased in the nutmeg treated group compared with control $(7.83 \pm 10.5 \mathrm{vs} 00 \pm 00)$, this increase showed significant decrease in the protected group (4.3 \pm 8.1 ). In nutmeg treated brains, there was a significant increase in GFAP-positive cells (cytoplasm of astrocytes) compared with control (29.86 $\pm 1.1 v s 9.98 \pm 0.68)$, this increase was significantly decreased in protected brains (21.32 \pm 1.8 ) (Figures 1-6).

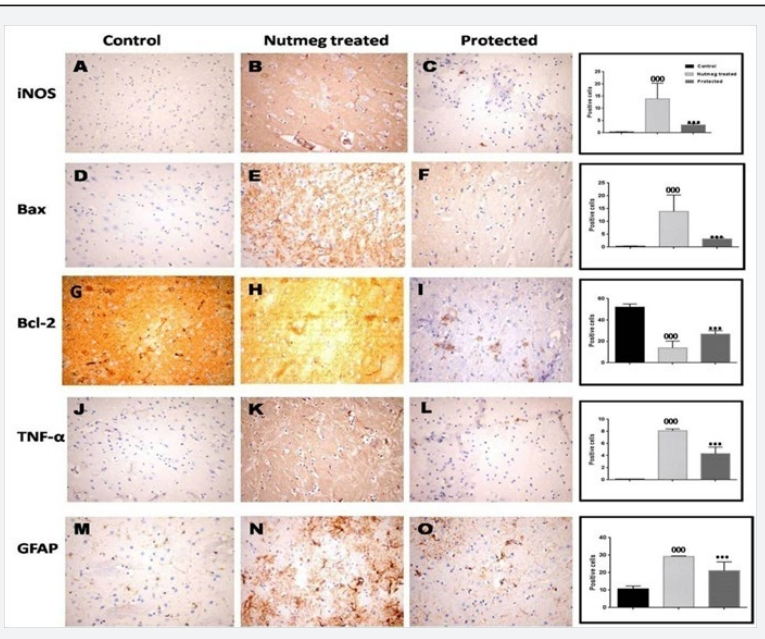

Figure 6: Representative immunostainingin layers II and III of different experimental groups showing that, iNOS and Bax-protein immunoreactive cells were increased in nutmeg-treated group ( $B$ and $E)$. These increases were reduced in the protected group ( $C$ and $F$ ). $\mathrm{Bcl}-2$ protein immunoreactive cells were decreased in nutmeg-treated rats $(\mathrm{H})$. These increases were reduced in the protected group $(\mathrm{I})$. Vitamin $C$ treatment attenuated the nutmeg-induced increase in TNF- $\alpha(J-L)$, GFAP expression (M-O).Inserts show a higher magnification of the boxed regions. ${ }^{* * *} \mathrm{P}<0.001$, compared with the nutmeg treated group; $000 \mathrm{P}<0.001$, compared with control. $\mathrm{N}=5$ for each group. Immunoperoxidase technique, $\times 400$.

\section{Discussion}

There is a wide range of ways to use nutmeg for various purposes. Five centuries ago [15], nutmeg has been used for its psychoactive pharmacologic properties, which includes anxiogenic, hallucination and anti depressant [16]. Powdered nutmeg is a constituent of large variety of medications such as aromatic adjuncts, but it is rarely used alone. It is usually introduced as flavoring food additive [17]. Also, it is used as psychoactive, anticonvulsant and aphrodisiac agent in male [18]. Medicinally, nutmeg is known as having anti-thrombotic, anti-inflammatory, stimulant, carminative and anti-rheumatic characters [19]. Myristicine, which has neurotoxic actions on dopaminergic neurons and monoamine oxidase is one of the active ingredients in nutmeg [20]. However, nutmeg may be associated with toxic states and it is a cause of health dangers when it comes to the intoxication units [21]. It has been noticed to harm cell viability in a dose dependent way [22].

The cingulate cortex, as a part of limbic system, is one of the brain areas that play an essential role in human reinforcement and reward processing, including both addiction 
and maintenance behavior [23]. The aim of the present study was to demonstrate the effect of nutmeg on the structure of the ventral anterior cingulate cortex (area 24a) in adult male albino rats, and to evaluate the protective role of vitamin $\mathrm{C}$. In the group of animals treated with nutmeg (group II), the neurons of the ventral division of the anterior cingulated cortex showed profound degenerative changes. There was vacuolated cytoplasm in its layers. Some cells with pyknotic nuclei could be seen. Most of the granule cells showed apparent reduction in Nissl granules as compared with the control group.

Many studies, on rat or mice liver, kidneys and brain, were performed and showed cytoplasmic vacuolizations associating the administration of nutmeg $[24,25]$. The effect of the aqueous extract of nutmeg seeds on the kidney and the liver of mice was also studied and showed similar effects. Kidney sections from nutmeg treated mice, showed some degenerative pathological changes of hydropic type. Besides, liver sections showed degenerative cellular changes of hydropic type (hypopigmentation and swelling), cellular vacuoles, fatty degeneration and some nuclear changes [26]. The nuclear changes included redistribution of chromatin granules and its adherence to the nuclear membrane. These changes were considered as pre-necrotic. These effects were evident in the nutmeg-treated mice and increased in a dose dependent manner. Furthermore, the cytotoxic edema usually includes intracellular swelling and this could also involve neuronal cells. The typical brain edema is accompanied with neuronal cell vacuolation and endothelial cell hypertrophy [22]. Brain edema is also generally accompanied with electrolyte imbalance. Therefore, nutmeg intoxication is thinkable to be associated with electrolyte imbalance. Cellular vacuolation may be due to permeability disorders of the membranes, caused by the reactive oxygen radicals, with consequent enhanced transport of water and electrolytes into the cell. Based on that, all cellular organelles will also be affected in the form of swelling and possible destruction [20].

Other researchers explained that intense vacuolation, in mammalian cells, leaded to subsequent cell death or apoptosis (necrotic shrinkage, the cell cytoplasm becoming intensely dense and crowded) and this is compatible with our finding of hyperchromatism as well as pyknotic nuclei. The affected cells might be expected to compensate for that by vacuolating and swelling. The cell membrane must become more permeable during apoptosis, since that compensation does not occur in the vast majority of cases. Vacuoles noticed in the apoptotic cells tend to be either autophagic or lipid filled vacuoles [27]. Moreover, presence of congested blood vessels was a very prominent feature in nutmeg treated rats. This agreed with Eweka, [25] who studied the effect of nutmeg on several organs. He noticed the presence of congested blood vessels in the kidney and liver. He explained that such dilated and congested blood vessels might be a part of inflammatory reaction response to bring more blood flow to the areas of degeneration or fibrosis.
Quantified immunohistochemical assessments were conducted to elucidate mechanism(s) of nutmeg neurotoxicity. A significant up-regulation of iNOS expression, a marker of oxidative distress was detected in the nutmeg treated group. It is hypothesized that iNOS generated NO could be one of the free radicals possibly produced in nutmeg neurotoxicity cases. However, iNOS plays a role in neuromodulation and neurotransmission. So, inappropriate expression of iNOS appears to be having deleterious effects as it is associated with brain damage and seizures [24]. The elevated expression of iNOS was associated with a significant increase in the number of Baxprotein positive nerve cells and endothelial cells with decrease in Bcl-2 protein immunoreactive nerve cells and endothelial cells of nutmeg treated rats compared with control rats. Bcl-2 family is known to be regulators of the mitochondrial release of cytochrome c. It is classified into two categories which are antiapoptotic proteins such as Bcl-XL and $\mathrm{Bcl}-2$ which reduce cytochrome release and pro-apoptotic proteins such as Bak and Bax that induce a loss of mitochondrial membrane potential and the release of cytochrome c. Thus, ratio of pro-apoptotic and anti-apoptotic Bcl-2 family may be a very important and pivotal key to the mitochondrial release of cytochrome $\mathrm{c}$ into the cytosol [28]. Therefore, in the present study, the expression of Bcl-2 family was examined immunohistochemically to elucidate the involvement of Bcl-2 in nutmeg induced apoptosis.

The expression of the inflammatory marker TNF- $\alpha$ was significantly increased in the nutmeg treated group compared with control. These results were supported by the results of others [22] who found that exposure to nutmeg in large amounts can cause inflammatory reactions. It has been noticed that with nutmeg exposure there should be an up regulation in various inflammatory chemokines and mediators. Glial fibrillar acid protein (GFAP) immunostaining is currently the most commonly used method to examine the distribution of astrocytes and detect their response to neural injury or degeneration. The current work showed that the number of GFAP-positive astrocytes increased significantly in nutmeg treated group that revealed positive immunoreaction in the cytoplasm and processes of many astrocytes producing a brushy or starry appearance. The alterations in astrocyte number are possibly because of oxidative stress and free radical formation. Also, these findings were in agreement with those of a study that deduced that the chemical and mechanical insults to the brain induce the hypertrophy and proliferation of astrocytes with elevated synthesis of intermediate filaments of glial type. This is a phenomenon called "reactive gliosis", which is defined as a universal reaction of astrocytes with specific functional and structural changes [29]. During the process of reactive gliosis, astrocytes produce and secrete neurotoxic substances such as free radicals and inflammatory cytokines, which have the ability to actively attack protein molecules within the neurons that results in neuronal damage, and contribute toward the pathogenesis of elucidation of neurodegenerative disorders [30]. 
Co-administration of nutmeg and vitamin $\mathrm{C}$ ameliorated the histological changes produced in area 24 from nutmeg toxicity. The cell has many protective ways for overcoming the effects of oxidative stress: by directly decreasing the occurrence of oxidative damage by means of antioxidants and/or by repairing the occurred damage. Vitamin C itself is a considerable part of the antioxidant system as it is considered a good hydrophilic on enzymatic antioxidant agent, and hence can ameliorate the oxidative stress and also has a number of biological activities, including immune response stimulation and alternation of metabolic activities of carcinogenic stressors [31]. Vitamin C probably alleviates the harmful mechanism of cellular damage by protecting the cells and tissues from oxidative damage by stimulating the regeneration of damaged tissues and cells and by scavenging oxygen-free radicals [32]. After their damage by nutmeg, vitamin $\mathrm{C}$ showed an improvement in the cell membranes, DNA and cytoplasmic organelles of somatotrophs and gonadotrophs. In this regard, another study [33] found that one of the causes associated with disruption of cell membranes was the enhancement of lipid peroxidation. Thus, vitamin C protects phospholipids from better peroxidation and prevents morphologic changes. For this reason, in the present study we chose vitamin $\mathrm{C}$ as a protective agent.

\section{Conclusion}

Long term consumption of nutmeg has adverse effect on the structure of the ventral anterior cingulate cortex. Coadministration of vitamin $\mathrm{C}$ improved these structural changes, most probably owing to its antioxidant and antiapoptotic functions. Further research, including human observational studies, aimed at corroborating these observations is recommended.

\section{References}

1. Alalwani AD (2013) Histological and cytological effects of aqueous extract of nutmeg on the renal cortical of male and female rats. Life science journal 10(1): 1240-1249.

2. Leela NK (2008) Chemistry of spices. CAB International, UK.

3. Malviya N, Jain S, Gupta VB, Vyas S (2011) Recent studies on aphrodisiac herbs for the management of male sexual dysfunction- A Review. Acta Pol Pharm 68(1): 3-8.

4. Olaleye M, Akinmoladun AC, Akindahunsi A (2006) Antioxidant properties of Myristicafragrans (Houtt) and its effect on selected organs of albino rats. African Journal of Biotechnology 5(13): 12741278 .

5. Zilles K, Wree A (1995) Cortex: areal and laminar structure. In: Paxions G, editor. Therat nervous system, ( $2^{\text {nd }}$ Edn.), Academic Press, Sydney, Oceania, pp. 649-683.

6. Krettek JE, Price JL (1997) The cortical projections of the mediodorsal nucleus andadjacent thalamic nuclei in the rat. J Comp Neurol 171(2): 157-191.

7. Vogt BA, Peters A (1991) Form and distribution of neurons in rat cingulate cortex:areas 32, 24, and 29. J Comp Neurol 195(4): 603-625.

8. Uylings HBM, Van Eden CG (1990) Qualitative and quantitative comparison of theprefrontal cortex in rat and in primates including humans. Prog Brain Res 85: 31-62.

9. Van Eden CG, Uylings HB (1995) Cytoarchitectonic development of the prefrontalcortex in the rat. J Comp Neurol 241(3): 253-267.

10. Gabbott PLA, Warner TA, Jays PRL, Salway P, Busby SJ (2005) Prefrontal cortex inthe rat: projections to subcortical autonomic, motor, and limbic centers. J Comp Neurol 492(2): 145-177.

11. Groenewegen HJ, Uylings HB (2000) The prefrontal cortex and the integration ofsensory, limbic and autonomic information. Prog Brain Res 126: 3-28.

12. Güney M, Demirin H, Oral B, Ozgüner M, Bayhan G, et al. (2007) Ovarian toxicity in rats caused by methidathion and ameliorating effect of vitamins E and C. Hum Exp Toxicol 26(6): 491-498.

13. Naidu KA (2003) Vitamin C in human health and disease is still a mystery? An overview. Nutr J 2: 7.

14. Bancroft JD, Gamble M (2002) Theory and practice of histological techniques, (5 ${ }^{\text {th }}$ Edn.), Churchill Livingstone, London, UK.

15. Brenner N, Frank OS, Knight E (1993) Chronic nutmeg psychosis. J R Soc Med 86(3): 179-180.

16. Dhingra D, Sharma A (2006) Antidepressant-like activity of n-hexane extract of nutmeg (Myristicafragrans) seeds in mice. J Med Food 9(1): 84-89.

17. Beyer J, Ehlers D, Maurer HH (2006) Abuse of nutmeg (MyristicafragransHoutt.): studies on the metabolism and the toxicologic detection of its ingredients elemicin, myristicin, and safrole in rat and human urine using gas chromatography/mass spectrometry. Ther Drug Monit 28(4): 568-575.

18. Barceloux DG (2009) Nutmeg (MyristicafragransHoutt.) Dis Mon 55(6): 373-379.

19. Prabuseenivasan S, Jayakumar M, Ignacimuthu S (2006) In vitro antibacterial activity of some plant essential oils. BMC Complement Altern Med 6: 39.

20. Youdim MB, Edmondson D, Tipton KF (2006) The therapeutic potential of monoamine oxidase inhibitors. Nat Rev Neurosci 7(4): 295-309.

21. Demetriades AK, Wallman PD, McGuiness A, Gavalas MC (2005) Low cost, high risk: accidental nutmeg intoxication. Emerg Med J 22(3): 223-225.

22. Lee BK, Kim JH, Jung JW, Choi JW, Han ES, et al. (2005) Myristicininduced Neurotoxicity in Human neuroblastoma SK-N-SH Cells. Toxicol Lett 157(1): 49-56.

23. Breiter HC, Aharon I, Kahneman D, Dale A, Shizgal P (2001) Functional imaging ofneural responses to expectancy and experience of monetary gains andlosses. Neuron 30(2): 619-639.

24. Adjene JO (2010) Histological effects of chronic consumption of nutmeg on the superior colliculus of adult Wister rats. Inter J Biomedical and Health Sci 6(2): 51-55.

25. Eweka AO (2010) EwekaAHistological effects of oral administration of nutmeg on the livers and kidneys of adult Wister rats. North Am J Medical Sci 2(4): 189-192.

26. Al-Hazmi M A, Assaggaf AI, Bin-Naser YS (2004) Effect of acute and sub chronic administration of nutmeg seed's extract on mice behavior, histological structure and biochemical functions. Saudi J Biol Sci 11(2): 177-188.

27. Henics T, Wheatley DN (1999) Cytoplasmic vacuolation, adaptation and cell death: A view on new perspectives and features. Biol Cell 91(7): 485-498. 
28. Howard S, Bottino C, Brooke S, Cheng E, Giffard RG, et al. (2002) Neuroprotective effects of bcl-2 overexpression in hippocampal cultures: Interactions with pathways of oxidative damage. J Neurochem 83(4): 914-923.

29. Baydas G, Reiter RJ, Akdemir I (2003) Melatonin reduces glial reactivity in the hippocampus, cortex, and cerebellum of streptozotocin-induced diabetic rats. Free Radic Biol Med 35(7): 797-804.

30. Bates KA, Fonte J, Robertson TA, Martins RN, Harvey AR (2002) Chronic gliosis triggers Alzheimer's disease-like processing of amyloid precursor protein. Neuroscience 113(4): 785-796.
31. Oral B, Guney M, Demirin H, Ozguner M, Giray SG, et al. (2006) Endometrial damage and apoptosis in rats induced by dichlorvos and ameliorating effect of antioxidant vitamins E and C. Reprod Toxicol 22(4): 783-790.

32. McCall MR, Frei B (1999) Can antioxidant vitamins materially reduce oxidative damage in humans? Free Radic Biol Med 26(7-8): 1034-1053.

33.Zreik TG, Kodaman PH, Jones EE, Olive DL, Behrman H (1999) Identification and characterization of an ascorbic acid transporter in human granulosa-lutein cells. Mol Hum Reprod 5(4): 299-302

\section{Your next submission with Juniper Publishers will reach you the below assets}

- Quality Editorial service

- Swift Peer Review

- Reprints availability

- E-prints Service

- Manuscript Podcast for convenient understanding

- Global attainment for your research

- Manuscript accessibility in different formats ( Pdf, E-pub, Full Text, Audio)

- Unceasing customer service

Track the below URL for one-step submission https://juniperpublishers.com/online-submission.php 